\title{
MRS reports election results for 2021
}

\author{
mrs.org/about-mrs/governance
}

$\mathrm{M}$

embers of the Materials Research Society (MRS) have elected a vice president (who will serve as president in 2022) and four directors to join the 2021 MRS Board of Directors. The Board is composed of the officers of the Society and 12 to 21 directors, $25 \%$ of whom may be appointed. The exact number shall be set by resolution of the Board of Directors.

The MRS Board of Directors is the highest governing body of MRS, responsible for establishing policy, monitoring progress of the Society toward its longterm goals, and setting the strategic directions for the activities of the Society, including its meetings, publications, interactions with government agencies, and cooperative efforts with other professional societies.

MRS directors are elected for threeyear terms. The president-elect serves three years (as president-elect, president, and past president); the secretary is elected for a three-year term; and the treasurer is appointed for an initial one-year term, which may be extended for two additional years (to complete a three-year term) with Board approval. Members of the Board may serve on one of the Board's committees (Executive, Finance and Audit, Governance), Board task forces, or other ad hoc efforts commissioned by the Board.

Terms of office expire at the end of the year indicated in parentheses. The asterisk (*) designates those who are newly elected. The annual election ended August 27, 2020.

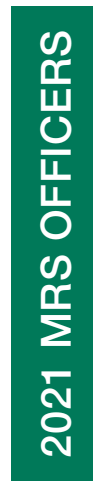

\section{President}

Cherie R. Kagan

University of Pennsylvania

Immediate Past President

Matt Copel

IBM T.J. Watson Research Center

Vice President (President-Elect)

* Carolyn R. Duran

Intel Corporation

\section{Secretary}

Dawnielle Farrar-Gaines

Johns Hopkins University

Treasurer

Shenda Baker

Synedgen Inc.

Executive Director

Todd M. Osman

Materials Research Society

*Newly elected.

* Ilke Arslan (2023)

Argonne National Laboratory

Leonard J. Brillson (2022)

The Ohio State University

Kristen H. Brosnan (2022)

Superior Technical Ceramics

* Kyoung-Shin Choi (2023)

University of Wisconsin-Madison

* Baratunde Cola (2023)

Georgia Institute of Technology/

Carbice Corporation

Coray M. Colina (2022)

University of Florida

Catherine Dubourdieu (2022)

Helmholtz-Zentrum Berlin/

Freie Universität Berlin

* Claudia Felser (2023)

Max Planck Institute for

Chemical Physics of Solids

Sarah Heilshorn (2021)

Stanford University
Frances A. Houle (2021)

Lawrence Berkeley

National Laboratory

MÔnica Jung de Andrade (2021)

The University of Texas

at Dallas

Sergei V. Kalinin (2021)

Oak Ridge National Laboratory

Center for Nanophase

Materials Sciences

Kisuk Kang (2021)

Seoul National University

Linda S. Schadler (2021)

The University of Vermont

Ting Xu (2022)

University of California,

Berkeley

Yusheng Zhao (2021)

Southern University

of Science and Technology

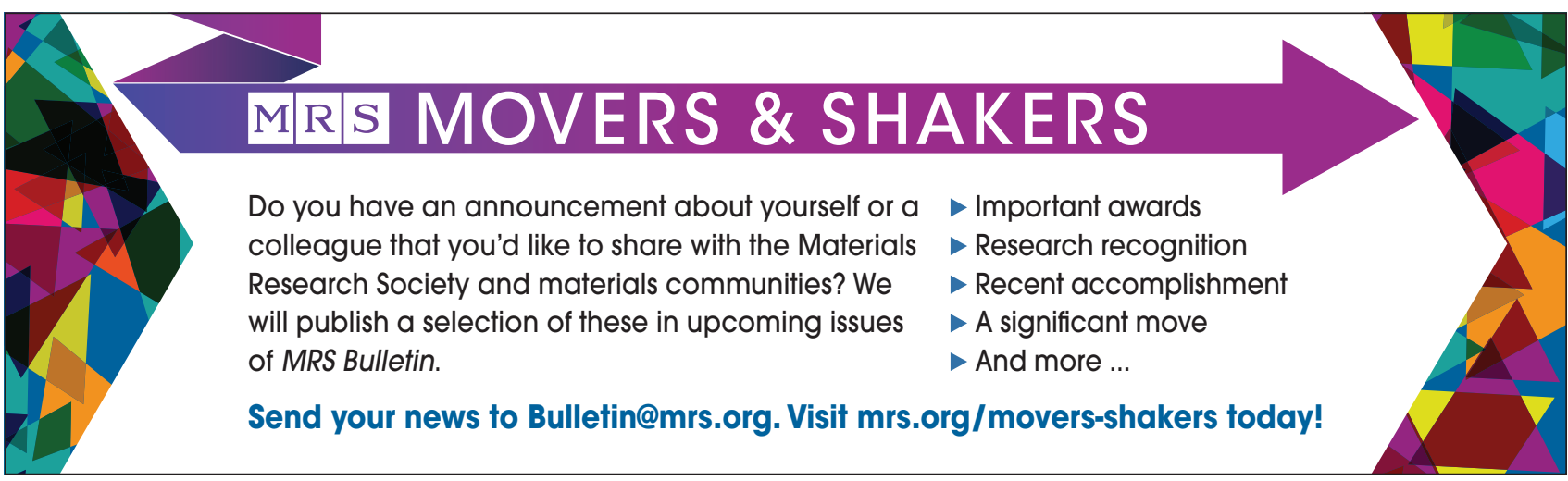

